\title{
PUBLIC EXAMINATIONS AT OXFORD
}

$\mathrm{T}$ WE report of the Committee on the Structure of the First and Second Public Examinations of the University of Oxford, issued in March 1965 as Supplement No. 3 to the University Gazette (and now published separately*), has thirty-two principal recommendations. The first of these is that, since the normal period of study for the first degree cannot be extended beyond three years, more of the top third of the students should be encouraged to stay on, either for a second Honours School or for a B.Phil. or Diploma course. No form of the First Public Examination should be based on less than three terms' work in the University, and the B.A. course should normally be divided so that each undergraduate without senior status has the opportunity of taking two examinations, each of medium size. Nevertheless, any faculty which so desires should be allowed to maintain an undivided Honour School at which candidates can satisfy the requirements of the First Public Examination and the Second Public Examination together at one time.

Provision is also recommended for new combinations of subjects and for "high level conversions" without reducing the standard of honours work and without multiplying separate examinations or special arrangements between faculties. New joint Schools linking the natural sciences and the humanities should be instituted where desirable by special arrangement on the patterns of the Final Honour School of Engineering and Economics. Teachers of the natural sciences in the university are recommended to consider together the possibility of establishing a comprehensive and integrated form of First Public Examination. This would give all students of science what they need in their first year while facilitating

- University of Oxford. Report of the Committee on the Structure of the First and Second Public Examinations. (Supplement No. 3 to the University Gazette, March 1965.) Pp. 141. (Oxford: The University, 1965.) $10 s$. the choices and changes which may be desirable before undergraduates are committed to their Final Honour Schools. The offer of supplementary subjects in a natural sciences course should be further encouraged and Honour Moderations in Classics and Theology retained as examinations to be taken after five terms.

On evidence of ability and industry supplied by his college, an undergraduate, unable by reason of sickness to sit Honour Moderations at the normal date, should be allowed to proceed with his studies as though he had passed, and the normal period of study for a single subject Final Honour School in modern humanities should be four terms for candidates who have already taken an Honour Moderations course of five terms. However, in appropriate cases a candidate who has already taken one such Final Honour School should be encouraged to offer himself for examination in another one year later. It should be possible for selected undergraduates to prepare themselves for examination in two short Final Honour Schools together seven terms after Honour Moderations, and the administration of the new arrangements suggested in the report should be entrusted to two new Boards, one for science and one for humanities.

Abolition of the Pass School is recommended, but an undergraduate who has to abandon hope of finishing a full Honours course should be given credit for what he has already done and be able to qualify for a degree, either by a reduced version of what he originally intended or by a wider and more elementary course constituted from pieces of the First Public Examination. Discussion of the structure of the University's examinations should proceed on the assumption that the University year will not be changed, and the University should negotiate with other British universities for greater uniformity in the titles of higher degrees.

\section{CODING RESPONSE OF N-FORMYL-METHIONYL-sRNA TO UUG}

\author{
By Dr. B. F. C. CLARK and DR. K. A. MARCKER \\ Medical Research Council Laboratory of Molecular Biology, University Postgraduate Medical School, Cambridge
}

$\mathrm{R}^{\mathrm{s}}$ ECENTLY, it was established that methionyl-sRNA is partly converted to $N$-formyl-methionyl-sRNA in a cell-free system from Escherichia coli ${ }^{1}$. The function of $N$-formyl-methionyl-sRNA in relation to the biosynthesis of protein has not been elucidated so far. We have investigated the coding characteristics of methionyl$s \mathrm{RNA}$ and of $N$-formyl-methionyl-sRNA by using them as sources of amino-acids for poplypeptide synthesis in a cell-free system and by binding them to ribosomes in the presence of specific triplets.

Studies of the $T-1$ ribonuclease digestion products of unfractionated partially formylated methionyl-sRNA showed that at least two methionyl-sRNA species exist in $E$. coli, and at least one of them cannot be formylated ${ }^{2}$.

Nirenberg's group first reported that poly UG stimulated the incorporation of methionine into protein-like material ${ }^{8}$, but their later preparations of poly UG failed to do so ${ }^{4}$. Because preparations of poly UAG and of poly UAGC stimulated methionine incorporation, the codeword UAG, of unspecified sequence, was assigned to methionine $e^{4,5}$. In recent months, most possible ribonucleotide triplets of specified sequence have been assigned to one or other of the 20 naturally occurring amino-acids ${ }^{6,7}$, using the elegant technique of Nirenberg and Leder ${ }^{8}$. In particular, methionyl-sRNA was found to be coded for by the triplet $A_{U G}$.

We have been able to repeat the earlier observation that poly UG stimulates the incorporation of methionine into polypeptide using a partially purified $E$. coli cell-free system with negligible formylation activity and a polymer with a base analysis of $U / G=1 \cdot 6 / 1$. When $N$-formylmethionyl-sRNA or the means of formylation were added to the cell-free system, there was a clear increase in the rate of incorporation of methionine into polypeptide (Fig. 1).

We investigated the nature of a polypeptide product synthesized in vitro in a system involving an $S-30$ fraction $^{10}$ from $E$. coli $M R E 600$, poly UG, and a mixture of unfractionated methionyl-sRNA and $N$-formyl-methionyl-sRNA. The amount of ${ }^{35} \mathrm{~S}-$-methionine incorporated in this system was about 12 per cent that of ${ }^{14} \mathrm{C}$-phenylalanine. Interestingly, the analysis of the TCA-insoluble material revealed that 80-90 per cent of the incorporated methionine occurred as $N$-terminal $N$-formyl-methionine. This suggests that only the methionyl-sRNA which can be formylated responds to poly UG in a protein-synthesizing system. 